\title{
Susceptibility to Exacerbation in COPD
}

John R Hurst, University College London, London, UK

Antonio Anzueto, University of Texas Health Science Centre, US

Jørgen Vestbo, University of Manchester, UK

To The Editor

We welcome the recent report by the SPIROMICS investigators [1], repeating our 2010 ECLIPSE analysis [2] describing exacerbations in chronic obstructive pulmonary disease (COPD) over three years of follow-up in a prospective and well-characterised patient cohort.

The major differences between the studies are the inclusion of patients with mild (GOLD Stage 1) spriometric impairment in SPIROMICS, and that fewer patients in SPIROMICS than ECLIPSE reported exacerbations in the year prior to study entry ( $24 \%$ vs. $47 \%$ ). The relative proportions of GOLD stage $1 / 2 / 3 / 4$ patients were $25 / 45 / 22 / 8 \%(n=1105)$ in SPIROMICS and $0 / 44 / 42 / 14 \%(n=2138)$ in ECLSIPSE. With these differences in mind, and given that exacerbation frequency was associated with more severe airflow obstruction in both cohorts, the results are similar: we reported that $12 \%$ of the ECLIPSE cohort had frequent exacerbations in each of three years follow-up, and $23 \%$ were exacerbation-free for three years, with the majority following a more variable course (SPIROMICS reported $2 \%$ and $51 \%$ respectively). Moreover, for patients having no exacerbations in year 1 and year 2, 85\% in SPIROMICS and 74\% in ECLIPSE had no exacerbations in the third year, and for those having two or more exacerbations in years 1 and 2, 51\% in SPIROMICS and 71\% in ECLIPSE had $\geq 2$ exacerbations in the third year also. In both cohorts, by far the strongest predictor of future exacerbation risk was past exacerbation history. Specific percentages will inevitably vary between studies. Importantly, neither ECLIPSE nor SPIROMICS recruited representative populations. Similar messages do appear in large primary care databases [3], where the challenges are reliable COPD diagnosis and accurate recording of exacerbations.

Exacerbations contribute to much of the morbidity, mortality and therefore health-care costs associated with COPD. A stratified-medicine approach to the prevention of exacerbations is central to cost-effective delivery of health-care. In all patients with COPD, ask about past exacerbation events regularly, and as a minimum annually. Only deploy prevention interventions in those at risk of future events. Do not use these routinely in patients who are not at risk: relative resistance to exacerbations is the most stable phenotype and the reasons for this deserve further study. A further major unanswered question is how to escalate and de-escalate pharmacotherapy in response to changes in exacerbation frequency. Only by addressing such questions can we aim to improve the outlook for all our patients with COPD - whether they exacerbate frequently, intermittently, or never. 


\section{References:}

1. Han MK, Quibrera PM, Carretta EE, Barr RG, Bleecker ER, Bowler RP, Cooper CB, Comellas A, Couper DJ, Curtis JL, Criner G, Dransfield MT, Hansel NN, Hoffman EA, Kanner RE, Krishnan JA, Martinez CH, Pirozzi CB, O'Neal WK, Rennard S, Tashkin DP, Wedzicha JA, Woodruff P, Paine R 3rd, Martinez FJ; SPIROMICS investigators. Frequency of exacerbations in patients with chronic obstructive pulmonary disease: an analysis of the SPIROMICS cohort. Lancet Respir Med. 2017 Jun 28. pii: S2213-2600(17)30207-2. doi: 10.1016/S2213-2600(17)30207-

2. Hurst JR, Vestbo J, Anzueto A, Locantore N, Müllerova H, Tal-Singer R, Miller B, Lomas DA, Agusti A, Macnee W, Calverley P, Rennard S, Wouters EF, Wedzicha JA; Evaluation of COPD Longitudinally to Identify Predictive Surrogate Endpoints (ECLIPSE) Investigators. Susceptibility to exacerbation in chronic obstructive pulmonary disease. N Engl J Med. 2010 Sep 16;363(12):1128-38.

3. Reilev M, Lykkegaard J, Halling A, Vestbo J, Søndergaard J, Pottegård A. Stability of the frequent COPD exacerbator in the general population: A Danish nationwide register-based study. NPJ Prim Care Respir Med. 2017 Apr 17;27(1):25. doi: 10.1038/s41533-017-0029-7 